\title{
Relatos de branquitude entre um grupo de homens brancos do Rio de Janeiro
}

Accounts of Whiteness from a Group of White Men in Rio de Janeiro

Rapports de blanchitude entre un groupe d'hommes blancs de Rio de Janeiro

Valeria Ribeiro Corossacz

\section{CpenEdition}

\section{Journals}

Edição electrónica

URL: http://journals.openedition.org/rccs/5790

DOI: $10.4000 /$ rccs. 5790

ISSN: 2182-7435

\section{Editora}

Centro de Estudos Sociais da Universidade de Coimbra

Edição impressa

Data de publição: 1 Dezembro 2014

Paginação: 43-64

ISSN: 0254-1106

\section{Refêrencia eletrónica}

Valeria Ribeiro Corossacz, "Relatos de branquitude entre um grupo de homens brancos do Rio de Janeiro », Revista Crítica de Ciências Sociais [Online], 105 | 2014, colocado online no dia 03 dezembro 2014, criado a 19 abril 2019. URL : http://journals.openedition.org/rccs/5790 ; DOI : 10.4000/ rccs. 5790 


\title{
VALERIA RIBEIRO COROSSACZ
}

\section{Relatos de branquitude entre um grupo de homens brancos do Rio de Janeiro}

\begin{abstract}
Neste artigo apresento dados de uma pesquisa realizada entre homens de classe média-alta do Rio de Janeiro, que se autodefinem como brancos. A pesquisa se insere no debate dos critical whiteness studies e tem como objetivo compreender a branquitude para avançar no estudo do racismo na sociedade brasileira. A análise de trechos de entrevistas demonstra como alguns entrevistados recorrem à figura da própria babá negra para poder dar um contorno à própria branquitude, embora a neguem como dado social no restante da entrevista. Neste sentido, discuto como a experiência da branquitude para esses entrevistados se concretizou no entrelaçamento entre as hierarquias de cor, gênero e classe.
\end{abstract}

Palavras-chave: branquitude; homem branco; masculinidade; racismo; Rio de Janeiro (Brasil).

\section{Introdução}

Neste artigo proponho algumas reflexões sobre a branquitude a partir de um corpus de entrevistas realizadas no âmbito de uma pesquisa antropológica sobre branquitude e masculinidade (Ribeiro Corossacz, 2010; 2012; 2014; 2015). Entre 2009 e 2012, conduzi 21 entrevistas com homens que se autoidentificam como brancos de classe média-alta, com idade entre os 43 e os 60 anos. Três tinham ou haviam tido relações afetivas mais ou menos estáveis com homens, enquanto os outros com mulheres. Nessas entrevistas, tratei de diversos temas que dizem respeito às experiências biográficas relativas à construção da branquitude e da masculinidade. Neste artigo, irei me concentrar em um dos aspectos que vieram à tona nas entrevistas, a saber, como, para três dos homens entrevistados, a experiência da branquitude se concretiza no entrelaçamento entre as hierarquias de cor, gênero e classe na lembrança da figura da babá negra.

A pesquisa é o desdobramento de trabalhos anteriores sobre racismo e sexismo no Brasil, em que me concentrei nas experiências de pessoas de 
classe popular, em sua maior parte negras e mulheres (Ribeiro Corossacz, 2009). Com esta pesquisa pretendo prosseguir na análise do racismo e do sexismo na sociedade brasileira através do estudo das posições estruturalmente hegemônicas - branquitude e masculinidade - nesses dois sistemas sociais, mediante a análise das experiências e das percepções de um grupo específico de homens brancos. As análises produzidas pela literatura científica nos últimos cinquenta anos sobre grupos sociais que são objeto de diversas formas de domínio, exploração e exclusão socioeconômica e cultural na história da sociedade brasileira (os índios, os negros, as mulheres e os pobres) permitem considerar a posição do homem branco de classe média-alta e das elites uma posição estrutural de privilégio socioeconômico. ${ }^{1} \mathrm{Meu}$ interesse nesta pesquisa é compreender, em seu grau máximo de realização, a branquitude e a masculinidade no contexto brasileiro, entendidas como categorias sociais de "ponto de referência", a partir das quais se observam e se nomeiam os grupos sociais "diferentes" (Guillaumin, 1992).

Escolhi trabalhar com indivíduos pertencentes à classe média-alta, e não à elite, para me aproximar de um universo social numericamente mais vasto, sendo as elites, por definição, um grupo circunscrito, ainda que socialmente dominante. Com classe média-alta me refiro às camadas consideradas parte das classes A e B (ABEP, 2011), que representam o topo da pirâmide social. ${ }^{2}$

\section{Racismo e branquitude}

Os estudos sobre a branquitude, identificados posteriormente com o rótulo critical whiteness studies, amadureceram nos Estados Unidos nos anos 1990 e são marcados por um empenho político e científico contra o racismo. ${ }^{3}$ Trata-se de um campo de estudos multidisciplinar, no qual a perspectiva histórica muitas vezes convive com a sociológica e antropológica. A análise da branquitude deve ser entendida como parte do mais amplo debate político e científico sobre o racismo, no qual é necessário reconhecer o papel fundamental desempenhado por ativistas e estudiosos/estudiosas negros/ /negras ao revelarem a necessidade de estudar a posição e as ações sociais daqueles que se classificam como brancos, para compreender a produção

\footnotetext{
${ }^{1}$ Para algumas referências em relação à condição dos negros, ver Hasenbalg (1979), Oliveira et al. (1985), Hasenbalg e Silva (1992), Guimarães (1999; 2002), Paixão (2003); quanto à condição das mulheres brancas e negras ver Berquó (1987), Silva Bento (1995), Lima (1995), Souza-Lobo (1991), Bruschini e Lombardi (2002), Bruschini (2007).

${ }^{2}$ Segundo um recente estudo, a classe A é formada por $82,3 \%$ de brancos e $17,7 \%$ de negros (cf. http://www.estadao.com.br/noticias/nacional,brancos-tem-duas-vezes-mais-acesso-a-planos-de-saude-no-brasil-que-negros,799485,0.htm, última consulta a 05.11.2014).

3 Para uma apresentação do panorama dos critical whiteness studies, ver Frankenberg (1999); Nayak (2007), Twine Winddance e Gallagher (2008).
} 
do racismo. Em sua experiência de luta contra o sexismo $e$ o racismo, as feministas negras americanas estiveram entre as primeiras a reconhecer a branquitude como condição social, cujas características devem ser analisadas (Hull, Bell Scott e Smith, 1982; Anzaldúa, 1987; Lorde, 2007). Também no Brasil, ao chamarem a atenção para o modo como o racismo determina as experiências de sexismo, as feministas negras identificaram a branquitude como condição social não transparente, não neutra (Gonzalez, 1983; Ribeiro, 1995).

Os estudos sobre a branquitude demonstraram como a condição social do branco varia de acordo com a época histórica e os contextos culturais. A branquitude deve ser entendida como um processo histórico e cultural e não como um fato em si (Frankenberg, 1999 e 2001). Ao me referir a essa abordagem, com "branco" pretendo indicar uma posição em uma estrutura social racializada, ou seja, em uma estrutura marcada pelo racismo, e não um dado por si só autoevidente. "Branco" é um rótulo que não tem nenhum significado fora do sistema social em que existem as categorias raciais e na ausência de outras identidades sociais construídas, como a de negro, índio e asiático. Conforme escreve Guimarães "alguém só pode ter cor e ser classificado num grupo de cor se existir uma ideologia em que a cor das pessoas tenha algum significado. Isto é, as pessoas têm cor apenas no interior de ideologias raciais" (1999: 44).

Nas sociedades marcadas pela colonização europeia e pelo racismo, a condição de branco implica o acesso a uma série de vantagens sociais, econômicas e de status (Du Bois, 1935; Baldwin, 1984; Harris, 1993; McIntosh, 1997; Frankenberg, 2001). Portanto, a branquitude se caracteriza por exprimir uma posição de privilégio estrutural, determinada por uma combinação de fatores históricos e mecanismos ligados à sua reprodução no presente (Lipsitz, 1995). Todavia, nem todas as pessoas definidas como brancas tiram proveito da branquitude do mesmo modo. Com efeito, a branquitude não é uma categoria uniforme ou monolítica, ela é sempre caracterizada por outras variáveis, como gênero, sexualidade, classe, status, religião, idade, nacionalidade, que precisam ser levadas em conta na análise etnográfica (Frankenberg, 1999 e 2001). Segundo Frankenberg, falar de branquitude deve, portanto, ser entendido sempre como um exercício de localização: temos de estar conscientes da necessidade de subtrair essa categoria, que se coloca como universal, da dimensão do geral, para, por sua vez, radicá-la em um espaço-tempo bem preciso (1999). Isso também implica estar consciente de que a definição de branquitude muda de acordo com quem a percebe e com quem a estuda, seja um branco, seja um negro, seja um índio. Com efeito, a branquitude se apresenta aos brancos como algo normal, automático, muitas vezes transparente, mas não se apresenta 
do mesmo modo para quem não é branco (Morrison, 1992; hooks, 1999; Ahmed, 2004).

Os primeiros estudos sobre a branquitude no Brasil surgiram no final dos anos 1990, acolhendo os trabalhos que estavam sendo publicados nos EUA. ${ }^{4}$ Embora os critical whiteness studies se refiram, na maioria das vezes, ao contexto dos Estados Unidos, eles oferecem várias sugestões importantes para o estudo da branquitude no contexto brasileiro a partir do uso da noção de branquitude, que, se radicada na sociedade brasileira, pode ajudar a compreender "o discurso brasileiro sobre as relações raciais" (Sovik, 2004: 364). Seguindo as observações de Sovik, podemos dizer que não se trata, portanto, de uma categoria importada e sim de um aspecto do racismo, cujo estudo é necessário. Ware considera que a análise da branquitude, identificada como prestígio social, permite relacionar o racismo no Brasil àquele de outros países (2004: 8).

O sociólogo Guerreiro Ramos representa uma importante exceção, uma vez que, já em 1957, analisara as características da condição dos brancos no Brasil, reconhecendo, assim, sua centralidade para o estudo do racismo. Segundo Guerreiro Ramos, os brancos no Brasil são uma minoria, apesar de que, "no plano ideológico, é dominante a brancura como critério de estética social” (1957: 172), que é definida segundo os critérios europeus. Diante dessa situação em que convivem sentimentos contrastantes - querer identificar-se como branco, mesmo sabendo que não se corresponde à estética social do branco europeu -, os brancos reagem recordando de modo demasiado frequente as próprias origens europeias ou se concentrando no estudo dos negros, ante os quais sua branquitude é confirmada. Portanto, Guerreiro Ramos se ocupa de um branco que se sente imperfeito se confrontado com o branco europeu, que é seu ponto de referência. O sociólogo observa ainda que, na linguagem comum, a designação de uma pessoa pela cor ocorre apenas para os negros: o "preto", o "negro". Nesses casos, "a cor humana perde o seu caráter de contingência ou de acidente para tornar-se verdadeiramente substância ou essência" (ibidem: 194). Com muita perspicácia, ele convida o leitor a "traduzir para o branco" as frases em que o sujeito é negro, para fazer notar a disparidade no uso substantivado dessas duas cores. Ainda hoje, a cor branca não funciona no plano da linguagem do mesmo modo que a cor negra; a definição "o branco" não poderia representar a pluralidade de aspectos que compõem a subjetividade de um indivíduo classificado como branco,

\footnotetext{
${ }^{4}$ Para algumas referências, ver Silva Bento (1999); Piza (2000; 2003); Norvell (2002); Carone e Silva Bento (2003); Pinho de Santana (2009); Sovik (2004; 2010). Uma primeira etapa dos estudos sobre branquitude pode ser considerada a produção científica sobre a teoria do branqueamento.
} 
que, portanto, merece ser nomeado não exclusivamente por sua cor. Desse modo, com suas observações, Guerreiro Ramos reconhecia o mecanismo da invisibilização como elemento central da branquitude. Atualmente, ainda é possível afirmar que os brancos no Brasil se tornaram pouco "visíveis" também em virtude do discurso sobre a valorização da mestiçagem, que representa a comunidade nacional como uma comunidade misturada, na qual seria difícil estabelecer quem é branco e quem é negro. Sovik fala de invisibilização do branco no discurso público (2010) para explicar como a branquitude é continuamente omitida no plano discursivo. A imagem do Brasil como sociedade misturada também está presente nas representações que cada indivíduo tem das próprias histórias familiares, fazendo com que o discurso nacional, o discurso público e o individual se sobreponham (Fry, 1996; Ribeiro Corossacz, 2009).

Todavia, é sempre necessário perguntar-se para quem os brancos são efetivamente invisíveis e em quais contextos o discurso da mistura na história familiar é ativado e valorizado por aqueles que são classificados como brancos. Com efeito, as pesquisas sobre o racismo e sobre a branquitude (Silva Bento, 1999; Piza, 2000 e 2003; Pinho de Santana, 2009; Maia, 2012) demonstram como esta última representa um valor do ponto de vista estético (identificável com ascendências europeias) e social (portadora de status), que orienta materialmente as relações sociais e os percursos biográficos.

Um dos objetivos desta pesquisa é analisar quais os critérios empregados pelos entrevistados para definir a si próprios e os outros como brancos, bem como as subsequentes reflexões sobre a branquitude. Em um trabalho anterior, analisei como a condição socioeconômica é um dos registros mais frequentes nos discursos dos entrevistados para falar de branquitude. Em diversos momentos das entrevistas, a condição social de branco foi elaborada em termos socioeconômicos, de maneira que a classe se tornou a linguagem para descrever as características da branquitude. Tentei demonstrar como essa modalidade de definição da branquitude para os entrevistados tem como resultado reforçar a invisibilidade e a naturalização de sua condição de brancos. De fato, eles conseguem representá-la apenas ao se referirem à diferença de classe, não vendo a especificidade de sua posição em termos de cor (Ribeiro Corossacz, 2012).

Além de usar o registro da classe, três homens falaram de sua experiência de branquitude referindo-se à presença, em sua infância, da babá negra que cuidava deles. Nesse caso, a experiência de branquitude era narrada com referência a momentos da própria biografia, em cujo centro estava não apenas a dimensão de classe, mas também relações afetivas entre os gêneros. Para poder ler essas representações da branquitude foi necessário 
não somente introduzir outra variável sociológica - o gênero -, mas também considerar de que modo uma combinação específica de hierarquias de cor, gênero e classe produzia essa experiência de branquitude. Com efeito, diferentemente das definições que se baseavam apenas no registro da classe, o discurso sobre a branquitude que examinarei aqui é explicitamente posicionado no que se refere às relações entre os gêneros. $\mathrm{O}$ aspecto saliente desses testemunhos é que são os únicos em que os entrevistados elaboraram explicitamente o discurso sobre a branquitude, fazendo referência a sujeitos sexuados, porém, como veremos, não sexualizados.

$\mathrm{Na}$ literatura brasileira sobre masculinidades, a discussão sobre a relevância da variável "cor" se encontra sobretudo em análises histórico-literárias ou que focam experiências de masculinidades negras, ou em condição de marginalidade social e/ou definidas como não normativas. ${ }^{5}$ Connell (1995) elaborou uma interpretação das masculinidades ocidentais, identificando um modelo de masculinidade hegemônica cujo perfil sociológico é próximo ao de uma parte dos entrevistados, ou seja, homens brancos heterossexuais de classe média e escolarizados.

\section{Os entrevistados: brancos em um mundo de brancos}

Atualmente, o Rio tem uma população de pouco mais de seis milhões de habitantes, dos quais cerca de 3600000 são brancos, 1800000 são pardos e 664000 são negros. ${ }^{6}$ Os bairros em que residem os entrevistados fazem parte da Zona Sul, região mais rica e valorizada da cidade, mesmo com a presença de numerosas favelas, enquanto a Zona Norte é a região menos valorizada. $\mathrm{Na}$ cidade do Rio, a distribuição dos grupos de cor varia segundo as regiões: na Zona Sul, pardos e negros são apenas $16 \%$ da população; os brancos formam $84 \%$, mas em alguns bairros o porcentual de brancos chega a $93 \%$ (Garcia, 2009: 184). Esses dados são confirmados por esta pesquisa: no momento da entrevista, sete homens viviam em um edifício em que havia um morador negro, uma exceção em relação ao restante dos vizinhos, identificados como brancos, e dois entrevistados tinham tido, no passado, um vizinho negro.

O contato com as pessoas encontradas ocorreu por meio de vários canais: amigos, parentes, conhecidos e os próprios entrevistados, aos quais pedi que me indicassem um homem branco de classe média, residente na Zona

\footnotetext{
${ }^{5}$ Vejam-se Cecchetto (2004); Pinho (2005; 2012); Miskolci (2012). A pesquisa de Piscitelli (2004) sobre fundadores de importantes grupos empresariais não discute o peso da variável cor, que parece implícita na de origem nacional.

${ }^{6}$ Os dados são de 2008 e foram extraídos do site do município do Rio de Janeiro (www.armazemdedados.rio.rj.gov.br).
} 
Sul e disponível para a entrevista. Essa variedade de canais no contato com os entrevistados me deu a possibilidade de encontrar pessoas originárias de ambientes diferentes, que formaram um grupo não homogêneo. Dada a metodologia usada para construir o grupo de entrevistados, o objetivo desta pesquisa não é apresentar uma amostra representativa das tipologias de habitantes brancos da Zona Sul, uma área da cidade muito vasta e diversificada em seu interior, mas ilustrar algumas trajetórias biográficas que ofereçam elementos úteis para uma reflexão mais ampla das experiências de branquitude. É importante ressaltar, todavia, que todos os entrevistados - tanto os que nasceram na Zona Sul, quanto os que vieram da Zona Norte - sentem suas vidas como típicas da Zona Sul, uma área da cidade vista como contraposta à Zona Norte em termos de classe e status, categorias que durante a entrevista foram declinadas também em termos de cor.

Todos os entrevistados possuem terceiro grau completo e alguns o título de doutor. A maior parte trabalha como profissional liberal ou funcionário público. Os entrevistados vêm de famílias que eles identificam como brancas ou misturadas. Ninguém se encontra em uma relação estável com uma mulher negra ou com um homem negro. Nem todos têm filhos, mas os que têm os definem como brancos. Portanto, se muitos identificaram a família de origem como misturada, ninguém definiu como tal a família que criou, identificada como branca. Note-se que, para as pessoas entrevistadas, o conceito de família misturada inclui a presença de imigrantes europeus e, em alguns casos, de indígenas, mas não a de descendentes de africanos. Este elemento permite explicar como é possível definir a própria família como branca, tal como a si mesmo, inclusivamente nos casos em que se afirma provir de uma família misturada. A valorização da mestiçagem, presente nos discursos destes homens, seria declinada por eles de forma seletiva, sem a presença do polo negro e africano, permitindo-lhes se considerarem brancos e misturados ao mesmo tempo.

Exceto por alguns casos raros, os amigos atuais e de infância desses homens são exclusivamente brancos. A característica dessas pessoas é ter vivido durante a infância e a adolescência em um ambiente em que os negros estavam presentes, mas quase sempre no mundo dos serviços (faxineiras, jardineiros, babás, serventes). Em alguns casos, verificou-se aquela que foi recordada como uma forma de intimidade afetiva com pessoas negras (companheiros de brincadeiras, empregadas), mas não parece ter havido uma experiência de igualdade social com crianças ou adultos classificados como negros. Muitos declararam ter encontrado pessoas negras ao longo do dia apenas em posições subordinadas (as mesmas considerações são feitas por Sheriff (2000) e Goldestein (2003). 


\section{A entrevista: falar de racismo sem mencionar a branquitude}

As entrevistas, todas gravadas, se baseiam em uma abordagem biográfica, na qual peço ao entrevistado que percorra alguns momentos de sua vida através de um olhar que se detenha na própria cor e naquela das pessoas de seu convívio, bem como nas experiências de masculinidade. Trata-se, portanto, de um material etnográfico em que peço às pessoas não apenas para reconstruírem as próprias lembranças, mas também para delas fazerem uma leitura, partindo da troca ocorrida durante a entrevista.

A classificação social da minha pessoa em termos de cor, classe e gênero foi um elemento importante no desenvolvimento da entrevista. $\mathrm{O}$ acesso aos homens entrevistados foi condicionado sobretudo pelo fato de considerar-me e de ser considerada uma mulher branca de classe média e pelo fato de residir na Zona Sul, durante minhas estadias no Rio. A classificação social da minha cor e da minha classe fez com que os meus interlocutores me identificassem como alguém que lhes era semelhante. Por alusões e referências que remetiam principalmente ao fato de eu viver na Europa e ser pesquisadora universitária, ou seja, de ter um capital cultural particularmente apreciado, os meus interlocutores demonstraram considerar-me "alguém como eles", mesmo que essa "semelhança" nunca fosse explicitada em referência à cor. Todavia, quando se tratava de responder às perguntas relativas à branquitude, predominava um misto de incredulidade, estranheza e resistência, que produzia silêncio e embaraço. Para alguns, o fato de que eu, considerada branca, fizesse essas perguntas era uma surpresa. Às vezes, tive a sensação de estar rompendo algo semelhante a um tácito acordo: não se fala sobre como se sente por ser considerado e considerar-se branco. Como observa Back, “ter coisas em 'comum' não é necessariamente o pré-requisito para um diálogo elucidativo sobre a construção social da branquitude" (2002: 48). ${ }^{7}$ Em muitos casos, as perguntas sobre a branquitude foram acolhidas pelos entrevistados como uma ocasião para falar do racismo. É importante ressaltar como ocorreu esse desvio: falar de racismo respondendo a perguntas sobre a branquitude significa falar da condição dos negros, e não daquela dos brancos dentro do racismo. Portanto, há um deslocamento do objeto da entrevista por parte dos entrevistados, que, assim, não descreviam a branquitude, mas seus efeitos sociais sobre outras pessoas, os negros, vistos como vítimas do racismo. Esse comportamento é frequente, conforme demonstram algumas pesquisas sobre a

\footnotetext{
7 Velho (2003) propõe importantes considerações sobre a experiência de familiaridade e estranhamento nas etnografias brasileiras no meio urbano, focalizando a atenção sobre a dimensão de classe sem conotação de cor.
} 
branquitude (Frankenberg, 1993 e 2001), e representa um dos principais obstáculos para o desenvolvimento da entrevista.

No caso desta pesquisa, creio que a propensão para falar do racismo, ou da sua inexistência, também deva ser entendida como o efeito de pertencer a uma sociedade que, historicamente, pôs no centro da identidade nacional a convivência entre grupos de diversas cores, e como o resultado de um debate sobre o racismo, animado nos últimos anos pela introdução da política das cotas universitárias para estudantes que se autodefinem como negros (Steil, 2006; Fry et al., 2007).

\section{As hierarquias de cor, gênero e classe na experiência da branquitude}

Embora a contemporaneidade urbana seja o cenário da entrevista e das biografias dos entrevistados, os homens falaram de experiências que, às vezes, em suas próprias palavras, eram interpretadas através de modelos de relações entre gêneros e cores que remetem à história colonial do Brasil. Em particular, a relação social entre o homem branco em condição abastada e a mulher negra e pobre, empregada nos trabalhos domésticos e nas tarefas de cuidado, evoca um modelo tradicional de relações sociais entre cores, gêneros e classes que tem suas origens no Brasil colonial, aquele entre o descendente de colonos portugueses ou europeus e a sua família, e uma ou mais escravas de origem africana, que trabalhava e vivia em sua casa, também cuidando das crianças. ${ }^{8}$ Esse modelo de relações ao mesmo tempo sociais, de trabalho, servis e familiares foi apresentado como um dos pilares da formação do éthos cultural da nação brasileira por Freyre em seu texto Casa-grande e senzala (1933), reconhecido por todos os entrevistados como uma obra central para a definição da formação nacional. Note-se que, na fala dos entrevistados, foi estabelecida uma continuidade entre as posições sociais da época colonial, em que a diferença principal era entre patrão e escravo, e as da época pós-abolição, em que a classificação de cor/ /raça passa a ter um papel predominante que naturalizou as desigualdades sociais (Ribeiro Corossacz, 2005).

De forma geral, os entrevistados, independentemente de sua orientação sexual, recordaram a figura da babá, cuja idade varia, como uma pessoa afetivamente importante, com a qual se vivia uma dimensão de intimidade e de carinho dentro do espaço privado da casa. Segundo Ávila, no Brasil a memória da babá é parte do "status de classe" e "configura a estética burguesa” (2008: 69). Na adolescência, a figura da empregada doméstica já não

\footnotetext{
${ }^{8}$ A continuidade entre escrava e empregada doméstica é objeto de inúmeras análises, vejam-se Giacomini (1988); Melo (1989; 1998); Goldestein (2003).
} 
é mais colocada pelos entrevistados, hetero- e homossexuais, na dimensão da afetividade e sim na esfera sexual. Em outros momentos da entrevista, eles evidenciaram como o ambiente em que cresceram considerava normal ter na empregada uma mulher à disposição e abusar dela sexualmente na fase da adolescência (Ribeiro Corossacz, 2014; 2015). Nesses últimos casos, a cor da empregada doméstica nem sempre é mencionada, sendo ressaltada principalmente sua condição de mulher de classe popular. Nos testemunhos que seguem, é presente uma forte racialização da babá enquanto mulher que cuida e oferece carinho, sendo que essa posição anula a dimensão sexual atribuída à mulher negra quando identificada como trabalhadora doméstica.

Os trechos de entrevistas permitem analisar de que maneira a relação com mulheres negras que desempenharam tarefas de cuidado se mostrou como um núcleo de significado ao qual recorrer para falar da própria condição de branco ou aludir a ela.

Houve algum momento, em que você sentiu de forma mais clara a sua branquitude, em que você aprendeu de forma mais clara o que significa ser classificado como branco? Sim, pelos empregados da minha infância, que eram negros, e eu sou engenheiro civil profissional, e em todas as minhas obras os empregados eram negros ou nordestinos; então é muito claro que essas etnias, se assim podem ser chamadas, são sempre as mais... as que pegam no pesado. O Brasil foi construído por negros, por escravos, depois por negros libertos, mas sempre fazendo aquilo que o branco nunca fazia. [...]

Quando você era criança, além desse momento, dessa relação com os empregados da casa, havia outros momentos em que você sentia essa questão da sua cor?

Bom, quando eu era criança, a babá, a empregada, o cara que chegava em casa para trazer a entrega eram todos negros.

Evocêpercebia isso...

Sim, com certeza.

\section{E o que você pensava, o que você sentia?}

Não sentia muita [diferença]..., percebia essa diferença, não sentia muito... Porque teve uma coisa muito engraçada e pitoresca. [Como] minha mãe, que era muito estressada porque trabalhava, não tinha leite, então eu mamei numa vizinha que era negra; e depois, as minhas duas babás, de [quando eu tinha] um ano de idade até quase oito, eram negras, então essa coisa de ter uma pessoa negra em casa que eu gostava, que cuidava de mim, não criou uma barreira para vê-los de forma diferente. (João, 55 anos) 
Houve algum momento em que você sentiu de forma mais forte a sua branquitude, em que você aprendeu de forma mais clara o que significa ser considerado branco?

Não, só... Isso eu via, que as pessoas fazem muita diferença. Curiosamente, eu não sentia isso, não sei explicar por quê, eu me sentia muito bem no meio de pessoas que fossem negras. Por exemplo, as empregadas normalmente são de origem negra no Brasil; salvo alguma nordestina, era tudo negro. Eu achava elas ótimas, me tratavam bem, eu adorava todas elas. Às vezes, meus pais tinham que sair e me deixavam na casa de uma delas que morava perto, ficava lá, num barraquinho lá. Eu achava ótimos os outros todos também, os filhinhos todos pretinhos, não via muita diferença não. (Luís, 56 anos)

\section{O que faz de um branco um branco?}

Eu não vejo... eu não consigo distinguir branco com branco. Minha babá negra foi sempre minha mãezona, eu tenho grandes amigos de todas as cores que eu possa imaginar, se é que se pode falar de cores; eu não consigo ver, não sei nem distinguir. Tem tanto branco esquisito, tanto negro esquisito, sei lá, acho que não tem definição. (Fernando, 52 anos)

Nesses trechos de entrevista, tento entender em que momentos da vida a pessoa desenvolveu uma consciência da branquitude, com que idade e de que modo entendeu o que significa identificar-se e ser identificado como branco e o que significa branco no contexto em que vive ou vivia. As respostas reportadas colocam no centro a figura da babá ou da empregada como pessoa, ao mesmo tempo, de referência no plano afetivo e naquele do trabalho de cuidado, e personagem lembrada - poderíamos dizer também utilizada - para responder às perguntas sobre a branquitude. Na infância de João e Luís, o mundo das pessoas que trabalham em casa, daqueles que se ocupam dos trabalhos manuais, de reprodução da vida material de uma casa e de seus moradores é identificado como o mundo dos negros e representa o espelho no qual se podem mirar, o contraponto àquilo que não se nomeia: a própria branquitude e aquela do ambiente com que o entrevistado se identifica. Conforme já observado, esse mecanismo de deslocamento é recorrente nas entrevistas: falar da cor dos outros (os negros) e não falar da própria foi um dos registros mais recorrentes para responder às perguntas sobre a branquitude. Aqui, assume um significado a mais devido à relação entre a figura do sujeito que fala, menino branco de família abastada, e aquela da babá negra. A percepção da própria condição de branco passa por uma relação, sentida e descrita como afetiva, com uma mulher negra e pobre. Todavia, além de ser uma relação afetiva individual, essa é uma relação social radicada em uma sobreposição histórica de hierarquias 
de cor, gênero e classe e que, ao mesmo tempo, as reproduz. Trata-se, simultaneamente, de uma relação afetiva de intimidade e desigualdade. ${ }^{9}$ João usa as palavras "engraçada e pitoresca" para descrever sua experiência: o fato de ter sido amamentado por uma mulher negra parece remeter a uma imagem folclórica, quase estereotipada e, no entanto, ainda real em uma grande cidade como o Rio dos anos $1950 .{ }^{10}$ Quando seus pais tinham de se ausentar, Luís era levado ao barraco onde morava a empregada negra e brincava com seus filhos, transitando livremente e com desenvoltura do mundo das casas dos brancos para o dos barracos pobres dos negros. No caso de Fernando, a mãezona é uma mulher negra que permanece por toda a vida a serviço da família, vivendo junto com ela. Todas essas são experiências individuais, sem serem referidas à própria cor, que evocam imagens da história do Brasil, das quais emerge um mapeamento do tecido social segundo classe, cor e gênero.

Reconhecer a própria branquitude por meio da figura da babá negra implica o fato de que a percepção de si mesmo como branco não ocorre de modo abstrato, mas passa por determinadas relações entre classes, gêneros e grupos de cor, tal como se definiram no processo de formação da nação brasileira e se rearticularam no decorrer do século Xx. Freyre representou essa relação entre a babá negra e o filho do senhor de engenho nordestino como um dos momentos em que se formou o caráter híbrido da cultura brasileira: "A figura da boa ama negra que, nos tempos patriarcais, criava o menino dando-lhe de mamar, que lhe embalava a rede ou o berço, que lhe ensinava as primeiras palavras de português errado" (1933: 323-324). Confrontadas com essa citação, as lembranças que vêm à tona com as palavras dos entrevistados fazem pensar que a relação de matriz colonial entre o menino branco de classe abastada e a babá negra e pobre se dilatou no tempo e no espaço, tornando-se quase perene. ${ }^{11}$ Como já observado, a figura da babá negra evoca, ainda que de modo distinto, aquela da empregada, muitas vezes negra, cuja sexualidade é considerada à disposição dos homens brancos, seus patrões. Ainda no trabalho de Freyre, vemos como é narrado esse continuum de relações sociais, cujo eixo ou ponto de referência implícito é o homem branco heterossexual e abastado:

\footnotetext{
${ }^{9}$ Segundo Goldestein, as relações patrão-empregada/o devem ser estudadas justamente porque são um caso em que existem relações de intimidade, apesar das fortes desigualdades de classe, típicas do Brasil (2003: 71).

${ }^{10}$ Deve-se notar que, na época, a família de João vivia em um bairro da Zona Norte.

11 Todavia, há que se considerar a faixa etária desses homens, que nos faz voltar no tempo. Seria extremamente interessante poder pesquisar as experiências dos atuais homens adolescentes brancos.
} 
[...] em tudo que é expressão sincera de vida, trazemos quase todos a marca da influência negra. Da escrava ou sinhama que nos embalou. Que nos deu de mamar. Que nos deu de comer, ela própria amolegando na mão o bolão de comida. Da negra velha que nos contou as primeiras histórias de bicho e de mal-assombrado. Da mulata que nos tirou o primeiro bicho de pé, de uma coceira tão boa. Da que nos iniciou no amor físico e nos transmitiu, ao ranger da cama de vento, a primeira sensação completa do homem. (Freyre, 1933: 279)

Mas quem é o "nós” de que fala Freyre? Quem pode identificar-se com esse "nós" e com essa história do Brasil? A característica da obra de Freyre é ter produzido uma leitura da experiência colonial e do caráter nacional do ponto de vista do homem branco heterossexual de classe alta, que, no entanto, se apresenta como $o$ ponto de vista da história brasileira. ${ }^{12}$ Como observa Needell, ao descrever o caráter dos brasileiros, Freyre "referia-se implicitamente aos brasileiros homens das elites brancas” (1995: 70).

Também nas narrações de alguns entrevistados encontramos esse modo de apresentar um si mesmo, cujo posicionamento dentro de relações sociais específicas entre classes, gêneros e grupos de cor é apagado. Luís afirma: "Por exemplo, as empregadas normalmente são de origem negra no Brasil; salvo alguma nordestina, era tudo negro". Passa-se de uma afirmação de caráter genérico ("as empregadas normalmente são de origem negra no Brasil”) para outra que, embora se mostre como a consequência do que foi dito antes, representa uma experiência particular: "salvo alguma nordestina, era tudo negro", em que se subentende "na minha casa”, ou seja, na casa de uma família de brancos de classe média. Para Fernando, para o qual não existem nem brancos, nem negros, sua experiência infantil com uma babá negra é considerada dentro da normalidade. Ainda é recorrente esse mecanismo em que a posição específica do homem branco de classe média torna-se a posição geral e neutralizada, a partir da qual se narra a sociedade.

Nessas entrevistas, além de ser usado para não responder às perguntas sobre a branquitude, o mecanismo de deslocamento do branco para o negro é empregado para sustentar que não houve uma socialização negativa em relação aos negros, e, para Fernando, de que não há uma diferença entre brancos e negros. Sua resposta significa: como eu poderia distinguir um branco de um negro se tive como babá uma mulher negra? Como posso

\footnotetext{
${ }^{12}$ As feministas negras foram as primeiras a propor uma análise crítica dessa representação da formação do Brasil e do papel que nela é atribuído à "relação sexual" entre o jovem senhor e a mulata, ver Gonzalez (1983).
} 
fazer uma distinção entre brancos e negros se, quando era pequeno, tive essa intimidade afetiva com uma mulher negra? Esta combinação entre desigualdade e intimidade é, ao contrário, uma das características das expressões do racismo brasileiro. A resposta de Fernando também tem como resultado a afirmação de que não é possível dar uma definição de branco, fazendo-nos pensar que o branco não existe. Para João, a lembrança da figura da babá negra parece ser ambivalente. Por um lado, parece ser a matriz da própria "indiferença" à cor (sua presença "não criou uma barreira para vê-los de forma diferente"), por outro, o momento em que começa a reconhecer como a sociedade em sua totalidade não é indiferente à cor e como isso conta na vida das pessoas. De modo direto e sem dificuldades, em outros pontos da entrevista, João afirma que as pessoas negras que encontra em sua vida estão sempre em uma posição subordinada, exceto no mundo da música, que ele frequenta por paixão. ${ }^{13}$ Portanto, ele admite que existe uma hierarquia social em que os negros ocupam as posições mais baixas e menos valorizadas. Luís também recorda um mundo em que "as pessoas fazem muita diferença" entre brancos e negros, enquanto vê a si mesmo como um menino que não fazia essa diferença, porque se sentia muito bem com suas babás negras e os filhos pretinhos delas. Todavia, hoje não convive com nenhum negro.

Desse modo, nos trechos de entrevista examinados, a figura da babá negra é lembrada com uma dupla finalidade: figuração de um mundo (mas deveríamos dizer de uma experiência de mundo) em que não há diferenças entre brancos e negros, além de ser a pessoa que permite dar um conteúdo à própria branquitude. Para esses homens, a percepção da própria branquitude, e a negação de seu impacto social, é um processo de que faz parte a figura da mulher negra que deles cuidou quando eram crianças numa relação que é apresentada como íntima e afetiva, cujos significados históricos e sociais de desigualdade são naturalizados. Nessas respostas, a branquitude é apresentada espontaneamente pelos entrevistados por meio do prisma da interconexão entre gênero, classe e cor, ainda que essa interconexão seja esvaziada de seus significados sociais.

Nessas narrações da branquitude, encontramos dois elementos centrais. O primeiro é a construção da experiência como branco por meio do Outro, nesse caso, um Outro que combina diversos eixos de alteridade (cor, gênero e classe), ou seja, por meio da Outra por antonomásia, a mulher negra e pobre. Essa modalidade nos coloca diante do fato de que a branquitude toma

${ }_{13}$ Essa divisão das esferas em que é possível uma convivência entre brancos e negros é discutida por Sansone (2004). 
forma no processo de construção da categoria social dos Outros (negros, índios), ou seja, de que esses dois polos estão ligados em um processo histórico de mútua constituição e não são independentes entre si (Frankenberg, 1996). Porém, enquanto para os brancos a branquitude aparece como um vazio, a condição dos negros/das negras é sempre adjetivada, sobretudo no negativo, mas não somente nele, de modo que transforma o branco em uma condição normativa a partir da qual os outros são caracterizados. O segundo elemento das narrações é justamente essa percepção da própria branquitude como uma condição normal, em que normal passa a coincidir com dominante segundo os eixos de cor, classe e gênero.

A racialização da babá não é acompanhada pela sua sexualização, ao contrário do que acontece com a figura da mulata (Corrêa, 1996) ou da empregada doméstica (Wade, 2013). Nos casos examinados, a relação de gênero com a babá, talvez por se referir à infância dos entrevistados, parece ter sido vivenciada de forma assexual. Essa relação poderia ser uma etapa importante para a produção, dentro do espaço doméstico, de certo gênero masculino branco de classe média.

\section{Conclusões}

Nestas páginas, explorei uma forma particular em que a branquitude foi experimentada por alguns homens brancos de classe média-alta, na qual aparece como central a intersecção das hierarquias de classe, cor e gênero. Em se tratando de observações com base em um grupo restrito, é possível apresentar algumas hipóteses iniciais de leitura e levantar algumas questões de caráter metodológico. O caráter fortemente homogêneo do ponto de vista da cor do mundo social dos entrevistados é um dos elementos que mais se faz notar. Exceto por algumas raras exceções, as pessoas identificadas como negras aparecem na vida dos entrevistados em posições subordinadas, sobretudo no mundo dos serviços e dos trabalhos manuais. Essa compacidade de cor do universo social do qual provêm os entrevistados contribui para uma percepção da própria branquitude como algo que não deve ser provado: eles fazem parte de um grupo que, embora muito amplo e diversificado em seu interior, está seguro da própria posição social de branco. Nesse sentido, trata-se de brancos que não correspondem à tipologia analisada por Guerreiro Ramos em 1957.

O material examinado evidencia que, para alguns entrevistados, a percepção da branquitude passa também pela figura da babá negra que tomava conta deles na infância. A babá apresenta-se na entrevista como uma figura em que se depositam diversos significados, à qual se recorre para poder dar um contorno à própria branquitude, mesmo a negando como dado social. 
Com efeito, mesmo que, para definir a própria branquitude, recorram a um modelo de relações sociais inscrito na intersecção das hierarquias de gênero, cor e classe, durante a entrevista os homens não veem as consequências dessa intersecção para sua posição social. A relação entre a babá negra e o menino branco de classe abastada aparece como uma relação normal. Ao reler o texto de Freyre sobre a formação da sociedade brasileira, ficou evidente como essa relação pode ser considerada normal apenas porque suportada por uma ideologia cultural, ainda hoje radicada, em que a sociedade brasileira é representada de um ponto de vista específico, que é aquele do homem branco heterossexual de classe abastada.

Essa normalização dos significados das experiências de branquitude nos leva a considerar as dificuldades metodológicas de um estudo sobre a branquitude, em particular quando esta é elaborada por homens de classe média-alta. Em alguns momentos da entrevista, houve, de fato, uma dupla neutralização do sujeito falante, de sua cor branca e de seu gênero masculino, sobretudo quando heterossexual, condições que são vividas como normais e, portanto, neutras, e não como posições particulares dentro de um sistema mais amplo de relações sociais. Durante a entrevista, os três homens homossexuais elaboraram um discurso sobre a experiência de "afastamento" da heterossexualidade vista como "normalidade". Todavia, a sua condição de classe e a definição de cor parecem ter lhes garantido um status de normalidade na relação com a figura da empregada doméstica negra, mesmo que eles possam ser percebidos como fora da norma no que se refere à orientação sexual. Ao longo da entrevista, foi difícil lidar com esse mecanismo de neutralização do próprio gênero e da própria cor e interagir com os entrevistados de forma que se pudesse desativá-lo. Em parte, o fato de ser considerada branca pelos meus interlocutores contribuiu para criar um ambiente em que a branquitude era vista como a normalidade, a respeito da qual, portanto, não era necessário indagar. Mesmo quando tentei desvincular-me desse mecanismo de identificação, persistiram as dificuldades para falar de sua experiência social como homem branco de classe média, uma situação que parecia sugerir que essa posição se situa no ápice da intersecção das hierarquias de cor, classe e gênero.

Apesar das importantes mudanças que a sociedade brasileira atravessou nas últimas décadas em relação ao racismo, os dados apresentados demonstram como em torno do tema da branquitude ainda existe um vazio: para os brancos a branquitude é uma espécie de buraco negro, cujo conteúdo de privilégio é difícil definir. 


\section{Referências bibliográficas}

ABEP - Associação Brasileira de Empresas de Pesquisa (2011), Critério de Classificação Econômica Brasil. Consultado a 03.03.2013, em http://www.abep.org/novo/Content. aspx?ContentID=301.

Ahmed, Sara (2004), "Declarations of Whiteness: The Non-Performativity of Anti-Racism”, borderlands ejournal, 2. Consultado a 03.03.2014, em http://borderlands. net.au/vol3no2_2004/ahmed_declarations.htm.

Anzaldúa, Gloria (1987), Bordelands / La Frontera: The New Mestiza. San Francisco: Aunt Lute Books.

Ávila, Maria Betania (2008), “Algumas questões teóricas e políticas sobre emprego doméstico”, in Maria Betania Ávila; Milena Prado; Tereza Souza; Vera Soares; Verônica Ferreira (orgs.), Reflexões feministas sobre informalidade e trabalbo doméstico. Recife: SOS CORPO, 65-72.

Back, Les (2002), “Guess Who's Coming to Dinner? Investigating Whiteness in the Gray Zone”, in Vron Ware; Les Back (orgs.), Out of Whiteness. Color, Politics and Culture. Chicago and London: The University of Chicago Press, 33-59.

Baldwin, James (1984), “On Being White...And Other Lies”, Essence, 90-92.

Berquó, Elza (1987), "Nupcialidade da população negra no Brasil”, Textos Nepo, 11, 8-45.

Bruschini, Cristina (2007), "Trabalho e gênero no Brasil nos últimos dez anos”, Cadernos de Pesquisa, 37(132), 537-572.

Bruschini, Cristina; Lombardi, Maria Rosa (2002), "Instruídas e trabalhadeiras. Trabalho feminino no final do século XX”, Cadernos Pagu, 17/18, 157-196.

Carone, Iray; Silva Bento, Maria Aparecida (orgs.) (2003), Psicologia social do racismo. Estudos sobre branquitude e branqueamento no Brasil. Petrópolis: Editora Vozes.

Cecchetto, Fátima Regina, (2004), Violência e estilos de masculinidade. Rio de Janeiro: Editora FGV.

Connell, Robert (1995), Masculinities. Sydney: Allen and Unwin.

Corrêa, Mariza (1996), "Sobre a invenção da mulata", Cadernos Pagu, 6/7, 35-50.

Du Bois, William Edward Burghardt (1935), Black Reconstruction in America, 1860-1880. New York: Harcourt.

Frankenberg, Ruth (1993), White Women, Race Matters. The Social Construction of Whiteness. Minneapolis: University of Minnesota Press.

Frankenberg, Ruth (1996), "Whiteness, and Americanness: Examing Constructions of Race, Culture, and Nation in White Women's Life Narratives”, in Steven Gregory; Roger Sanjek (orgs.), Race. New Brunswick, New Jersey: Rutgers University Press, 62-77.

Frankenberg, Ruth (1999), “Introduction: Local Whiteness, Localizing Whiteness”, in Ruth Frankenberg (org.), Displacing Whiteness: Essays in Social and Cultural Criticism. Durham, NC: Duke University Press, 1-33. 
Frankenberg, Ruth (2001), "Mirage of Unmarked Whiteness”, in Birgit Brander Rasmussen; Eric Klinenberg; Irene J. Nexica; Matt Wray (orgs.), The Making and Unmaking of Whiteness. Durham, London: Duke University Press, 72-96.

Freyre, Gilberto (1933), Casa-grande \& senzala. Formação da família brasileira sob o regime de economia patriarcal. Rio de Janeiro: José Olympio.

Fry, Peter (1996), “Por que o Brasil é diferente?”, Revista Brasileira de Ciências Sociais, 31, 178-182.

Fry, Peter; Maggie, Yvonne; Maio, Marcos Chor; Monteiro, Simone; Santos, Ricardo Ventura (orgs.) (2007), Divisões perigosas. Políticas raciais no Brasil contemporâneo. Rio de Janeiro: Civilização Brasileira.

Garcia, Antonia (2009), Desigualdades raciais e segregação urbana em antigas capitais. Salvador, cidade d'Oxum, e Rio de Janeiro, cidade de Ogum. Rio de Janeiro: Garamond.

Giacomini, Sonia (1988), Mulher e escrava: Uma introdução bistórica ao estudo da mulher negra no Brasil. Petrópolis: Vozes.

Goldestein, Donna (2003), Laughter Out of Place. Race, Class, Violence, and Sexuality in a Rio Shantytown. Berkeley/Los Angeles: University of California Press.

Gonzalez, Lélia (1983), "Racismo e sexismo na cultura brasileira", Ciências Sociais Hoje, 2, 223-244.

Guerreiro Ramos, Alberto (1957), "Patologia social do 'branco' brasileiro”, in Guerreiro Ramos, Introdução crítica à sociologia brasileira. Rio de Janeiro: Editorial Andes Limit, 171-192.

Guillaumin, Colette (1992), "Question de différence”, in Colette Guillaumin, Sexe, race et pratique du pouvoir. Paris: côté femmes, 83-106 [ed. orig.: 1979].

Guimarães, Antonio Sérgio Alfredo (1999), Racismo e anti-racismo no Brasil. São Paulo: Editora 34.

Guimarães, Antonio Sérgio Alfredo (2002), Classes, raças e democracia. São Paulo: Editora 34.

Harris, Cheryl I. (1993), "Whiteness as Property”, Harvard Law Review, 106, 1709-1791.

Hasenbalg, Carlos (1979), Discriminação e desigualdades raciais no Brasil. Rio de Janeiro: Graal.

Hasenbalg, Carlos; Silva, Nelson do Valle (1992), Relações raciais no Brasil contemporâneo. Rio de Janeiro: Rio Fundo Editora.

hooks, bell (1999), "Representing Whiteness in the Black Imagination", in Ruth Frankenberg (org.), Displacing Witheness. Essays in Social and cultural Criticism. Durham: Duke University Press, 164-179.

Hull, Gloria; Bell Scott, Patricia; Smith, Barbara (orgs.) (1982), All the Women Are White, All the Blacks Are Men, But Some of Us Are Brave. Old Westbury, N.Y.: The Feminist Press.

Lima, Márcia (1995), “Trajetória Educational e Realização Sócio-Econômica das Mulheres Negras”, Estudos Feministas, 3(2), 489-495. 
Lipsitz, George (1995), “The Possessive Investment in Whiteness: Racialized Social Democracy and the 'White' Problem in American Studies", American Quartely, 47(3), 369-387.

Lorde, Audre (2007), Sister Outsider: Essays and Speeches. Berkeley: Crossing Press. McIntosh, Peggy (1997), "White Privilege and Male Privilege: A Personal Account of Coming to See Correspondences through Work in Women's Studies”, in Richard Delgado; Jean Stefancic (orgs.), Critical White Studies. Looking Behind the Mirror. Philadelphia: Temple University Press, 291-299.

Maia, Suzana (2012), "Identificando a branquidade inominada: corpo, raça e nação nas representações sobre Gisele Bündchen na Mídia Transnational”, Cadernos Pagu, 38, 309-341.

Melo, Hildete Pereira de (1989), "Feminists and Domestic Workers in Rio de Janeiro", in Elsa M. Chaney; Mary Castro Garcia (orgs.), Muchachas no More. Housebold Workers in Latin America and the Caribbean. Philadelphia: Temple University Press, 245-267.

Melo, Hildete Pereira de (1998), Serviço doméstico remunerado no Brasil: de criadas a trabahadoras. Texto para discussão n. 565. Rio de Janeiro: IPEA.

Miskolci, Richard (2012), O desejo da nação. Masculinidade e branquitude no Brasil de fins do XIX. São Paulo: Annablume.

Morrison, Toni (1992), Playing in the Dark-Whiteness and the Literary Imagination. Cambridge: Harvard University Press.

Nayak, Anoop (2007), "Critical Whiteness Studies”, Sociology Compass, 1/2, 737-755.

Needell, Jeffrey D. (1995), "Identity, Race, Gender and Modernity in the Origins of Gilberto Freyre's Oeuvre”, American Historical Review, 100(1), 51-77.

Norvell, John M. (2002), “A brancura desconfortável das camadas médias brasileiras”, in Yvonne Maggie; Claudia Barcellos Rezende (orgs.), Raça como retórica. A construção da diferença. Rio de Janeiro: Civilização Brasileira, 245-268.

Oliveira, Lucia Helena; Porcaro, Rosa Maria; Araújo, Tereza Cristina (1985), O lugar do negro na força de trabalbo. Rio de Janeiro: IBGE.

Paixão, Marcelo (2003), Desenvolvimento bumano e relações raciais. Rio de Janeiro: Dp\&A editora.

Pinho, Osmundo (2005), "Etnografias do Brau. Corpo, Masculinidade e Raça na Reafricanização em Salvador”, Estudos Feministas, 13(1), 127-145.

Pinho, Osmundo (2012), "Race Fucker: representações raciais na pornografia gay”, Cadernos Pagu, 38, 159-195.

Pinho de Santana, Patrícia (2009), "White but not Quite: Tones and Overtones of Whiteness in Brazil”, Small Axe: A Caribbean Journal of Criticism, 13(2), $39-56$.

Piscitelli, Adriana (2004), “'Pioneiros': masculinidades em narrativas sobre fundadores de grupos empresariais brasileiros”, in Mônica Raisa Schpun (org.), Masculinidades. São Paulo: Boitempo, 175-202. 
Piza, Edith (2000), "Branco no Brasil? Ninguém sabe, ninguém viu”, in Antonio Sergio Alfredo Guimarães; Lynn Huntley (orgs.), Tirando a máscara. Ensaios sobre o racismo no Brasil. São Paulo: Paz e Terra/SEF, 97-126.

Piza, Edith (2003), "Porta de vidro: entrada para branquitude”, in Iray Carone; Maria Aparecida Silva Bento (orgs.), Psicologia social do racismo. Estudos sobre branquitude e branqueamento no Brasil. Petrópolis: Editora Vozes, 59-90.

Ribeiro Corossacz, Valeria (2005), Razzismo, meticciato, democrazia razziale. Le politiche della razza in Brasile. Soveria Mannelli: Rubbettino.

Ribeiro Corossacz, Valeria (2009), O corpo da nação. Classificação racial e gestão social da reprodução em hospitais da rede pública do Rio de Janeiro. Rio de Janeiro: Editora UFRJ.

Ribeiro Corossacz, Valeria (2010), "L'apprendimento della mascolinità tra uomini bianchi di classe medio-alta a Rio de Janeiro”, in Valeria Ribeiro Corossacz; Alessandra Gribaldo (orgs.), La produzione del genere. Ricerche etnografiche sul femminile e sul maschile. Verona: Ombre corte, 113-133.

Ribeiro Corossacz, Valeria (2012), "What Makes a White Man White? Definitions Teetering between Color and Class among White Men in Rio de Janeiro", Graduate Journal of Social Science, Special issue on Critical Whiteness Studies - Methodologies, 9(1), 22-45. Consultado a 31.10.2014, em http://www.gjss.org/index.php?/Volume-91-March-2012-Critical-Whiteness-Studies-Methodologies.html.

Ribeiro Corossacz, Valeria (2014), "Cor, classe, gênero: aprendizado sexual e relações de domínio”, Revista Estudos Feministas, 22(2), 521-542.

Ribeiro Corossacz, Valeria (2015), "Whiteness, Maleness and Power: A Study in Rio de Janeiro”, Latin American \& Caribbean Ethnic Studies, 10(2), no prelo.

Ribeiro, Matilde (1995), "Mulheres Negras Brasileiras: de Beritoga a Beijing”, Estudos Feministas, 3(2), 446-457.

Sansone, Livio (2004), Negritude sem etnicidade: o local e o global nas relações raciais e na produção negra do Brasil. Salvador/ Rio de Janeiro: Edufba/Pallas.

Sheriff, Robin (2000), "Exposing Silence as Cultural Censorship: a Brazilian Case”, American Anthropologist, 102(1), 114-132.

Silva Bento, Maria Aparecida (1999), "Institucionalização da luta anti-racismo e branquitude”, in Rosana Heringer (org.), A cor da desigualdade. Desigualdades Raciais no mercado do trabalho e ação afirmativa no Brasil. Rio de Janeiro: Ierê, 11-30.

Souza-Lobo, Elisabeth (1991), A classe operária tem dois sexos. Trabalbo, dominação e resistência. São Paulo: Editora Brasilienese.

Sovik, Liv (2004), "Aqui ninguém é branco: hegemonia branca e media no Brasil”, in Vron Ware (org.), Branquidade. Identidade branca e multiculturalismo. Rio de Janeiro: Editora Garamond/Afro - Centro de Estudos Afro-Brasileiros, 363-386.

Sovik, Liv (2010), Aqui ninguém é branco. Rio de Janeiro: Aeroplano Editora.

Steil, Carlos Alberto (org.) (2006), Cotas raciais na Universidade. Um debate. Porto Alegre: UFRGS Editora. 
Twine Winddance, France; Gallagher, Charles (2008), "Introduction: The Future of Whiteness: A Map of the 'Third Wave", Ethnic and Racial Studies, 31(1), 4-24.

Velho, Gilberto (2003), "O desafio da proximidade”, in Gilberto Velho e Karina Kuschnir (orgs.), Pesquisas urbanas. Desafios do trabalbo antropológico. Rio de Janeiro: Jorge Zahar Editor, 11-19.

Wade, Peter (2013), "Articulation of Erotization and Race: Domestic Service in Latin America”, Feminist Theory, 14(2), 187-202.

Ware, Vron (2004), “O poder duradouro da branquidade: 'um problema a solucionar'”, in Vron Ware (org.), Branquidade. Identidade branca e multiculturalismo. Rio de Janeiro: Editora Garamond, Afro, 7-40.

Artigo recebido a 17.03.2014

Aprovado para publicação a 31.10 .2014

\section{Valeria Ribeiro Corossacz}

Dipartimento di Studi Linguistici e Culturali, Università degli Studi di Modena e Reggio Emilia Largo Sant'Eufemia, 19 - 41121 Modena, Itália

Contacto: valeria.ribeirocorossacz@unimore.it 
